\title{
Different magnetic resonance imaging patterns after transcranial magnetic resonance-guided focused ultrasound of the ventral intermediate nucleus of the thalamus and anterior limb of the internal capsule in patients with essential tremor or obsessive-compulsive disorder
}

\author{
Hyun Ho Jung, MD, Won Seok Chang, MD, Itay Rachmilevitch, BSc, ${ }^{1}$ Tal Tlusty, BSc, ${ }^{2}$ \\ Eyal Zadicario, MSc, ${ }^{2}$ and Jin Woo Chang, MD, PhD'
}

'Department of Neurosurgery, Brain Research Institute, Yonsei University College of Medicine, Seoul, Korea; and ${ }^{2}$ InSightec, Haifa, Israel

OBJECT The authors report different MRI patterns in patients with essential tremor (ET) or obsessive-compulsive disorder (OCD) after transcranial MR-guided focused ultrasound (MRgFUS) and discuss possible causes of occasional MRgFUS failure.

METHODS Between March 2012 and August 2013, MRgFUS was used to perform unilateral thalamotomy in $11 \mathrm{ET}$ patients and bilateral anterior limb capsulotomy in 6 OCD patients; in all patients symptoms were refractory to drug therapy. Sequential MR images were obtained in patients across a 6-month follow-up period.

RESULTS For OCD patients, lesion size slowly increased and peaked 1 week after treatment, after which lesion size gradually decreased. For ET patients, lesions were visible immediately after treatment and markedly reduced in size as time passed. In $3 \mathrm{ET}$ patients and $1 \mathrm{OCD}$ patient, there was no or little temperature rise (i.e., $<52^{\circ} \mathrm{C}$ ) during MRgFUS. Successful and failed patient groups showed differences in their ratio of cortical-to-bone marrow thickness (i.e., skull density).

CONCLUSIONS The authors found different MRI pattern evolution after MRgFUS for white matter and gray matter. Their results suggest that skull characteristics, such as low skull density, should be evaluated prior to MRgFUS to successfully achieve thermal rise.

Clinical trial registration nos. NCT01932463 (for ET) and NCT01986296 (for OCD) (ClinicalTrials.gov)

http://thejns.org/doi/abs/10.3171/2014.8.JNS132603

KEY WORDS MR-guided focused ultrasound; thalamotomy; capsulotomy; skull density; essential tremor; functional neurosurgery; obsessive-compulsive disorder

$\mathrm{T}$ RansCranial MR-guided focused ultrasound (MRgFUS) is a technology that has evolved over the last decade as an incisionless alternative to surgery. $13,16,18,19$ Recent advances in transducer design, acoustic focusing technology, and MR thermometry enable the treatment of functional brain disorders by creating thermal lesions without opening the skull. ${ }^{13,16,18,19}$ This thermal lesioning technique has renewed neurosurgeons' enthusiasm for making lesions deep within the brain in a less invasive manner while avoiding potential side ef- fects of ionizing radiation. Neuropathic pain, essential tremor (ET), Parkinson's disease, and obsessive-compulsive disorder (OCD) are considered ideal conditions for MRgFUS because the necessary volume of lesioning is relatively small, thus requiring less energy to achieve therapeutic efficacy. $13,16,18,19$

We are currently engaged in investigations of the potential therapeutic efficacy and safety of MRgFUS for functional brain disorders such as ET and OCD. Recently, we reported clinical efficacy of MRgFUS thalamotomy

ABBREVIATIONS ALIC = anterior limb of the internal capsule; $\mathrm{ET}=$ essential tremor; MRgFUS = magnetic resonance-guided focused ultrasound; MRI = magnetic resonance imaging; OCD = obsessive-compulsive disorder; Vim = ventral intermediate.

SUBMITTED November 24, 2013. ACCEPTED August 21, 2014.

INCLUDE WHEN CITING Published online October 24, 2014; DOI: 10.3171/2014.8.JNS132603.

DISCLOSURE Both clinical trials are supported by InSightec (Haifa, Israel), and InSightec provided technical assistance for the present study. 
for $11 \mathrm{ET}$ patients with radiological outcomes. ${ }^{1}$ Also, we had the opportunity to undertake MRgFUS capsulotomy in OCD patients, which represented the first application to the human anterior limb of the internal capsule (ALIC). Here we report different MRI patterns after sonication of the ventral intermediate (Vim) nucleus of the thalamus and the ALIC in this study.

\section{Methods \\ Patients}

Between March 2012 and August 2013, 11 ET and 6 OCD patients underwent MRgFUS after providing informed consent. All patients were drug refractory and referred from movement neurologists or psychiatrists. We received full approval of clinical feasibility studies for patients with ET and OCD from the Institutional Review Board of the Human Research Protection Center of Severance Hospital (Seoul, Korea) and the Korean FDA. Moreover, this study was registered with the ClinicalTrials. gov database: the registration no. for ET is NCT01932463 and the registration no. for OCD is NCT01986296 (http:// clinicaltrials.gov). Procedures for the selection of patients and pre- and post-MRgFUS evaluation are outside of the scope of this paper.

\section{Anatomical Targets}

For ET patients, we targeted the unilateral Vim nucleus of the thalamus $(14 \mathrm{~mm}$ from the midline or $11 \mathrm{~mm}$ from the lateral wall of the third ventricle, $6 \mathrm{~mm}$ anterior to the posterior commissure along the intercommissural line). For OCD patients, we targeted the bilateral ALIC (approximately 7-8 $\mathrm{mm}$ anterior to the anterior margin of the anterior commissure, extending 2-3 $\mathrm{mm}$ along the capsule from a coronal view). Once the initial target coordinates for ET and OCD were confirmed, we made rigid lesions at the second coordinates, which were less than 4 $\mathrm{mm}$ apart from the initial coordinates.

\section{Magnetic Resonance-Guided Focused Ultrasound Procedure}

Magnetic resonance-guided focused ultrasound was performed in a 3-T MRI system (GE Medical System) using the ExAblate 4000 device (InSightec), which features a 30-cm-diameter hemispherical 1024-element phased-array transducer operating at $650 \mathrm{kHz}$ held by a mechanical positioner. Each patient's scalp was completely shaved, and the head was immobilized in a CRW stereotactic frame (Radionics). In the MRI room, the stereotactic frame was fixed to the table, which was a part of the ExAblate 4000 device. Presonication MRI was performed, and images were fused with CT scans and other MR sequences to determine target coordinates. Several low-power sonications of 10 -second duration were applied to induce peak temperatures of $40^{\circ}-42^{\circ} \mathrm{C}$, which are known to be below the permanent ablation threshold. This allowed us to visualize the exact position and size of the thermal spot and the overall safety profile of the applied sonication parameters. High-power sonications were then applied in an iterative process guided by MRI with Q-body coil and MR thermometry, with stepwise in- creases in acoustic power and energy to achieve a peak temperature in the target region between $51^{\circ} \mathrm{C}$ and $56^{\circ} \mathrm{C}$ for more than 3 seconds. All patients were fully awake and responsive during the entire procedure.

\section{MRI Sequences and Follow-Up Imaging}

After sonication using a 27-channel head coil, T1weighted imaging with and without contrast enhancement, T2-weighted imaging, diffusion-weighted imaging, and FLAIR were performed to detect the lesion. Based on the ET and OCD protocols, MRI was performed immediately, 1 week, 1 month, and 3 months after MRgFUS for ET, and immediately, 1 week, 1 month, and 6 months after MRgFUS for OCD. The serial volume of the lesion was measured using Leksell GammaPlan version 10.1 (Elekta $\mathrm{AB}$ ) on T2-weighted images.

\section{Results}

\section{MRI Patterns After Thalamotomy in Patients With ET}

Patterns of MRI changes were similar in the 8 successful ET patients, although there were 3 failed cases. Lesions in the Vim of the thalamus were visible in T2-weighted images taken during sonication (Fig. 1A). Lesions were also visible immediately after sonication. At this time point, there was strong enhancement of the lesion, presumably due to blood-brain barrier opening. One day after sonication, this enhancement disappeared, but local edema near the sonication site started to become prominent. Seven days after sonication, lesions were further enhanced and more distinct on T1-weighted images. One month after sonication, however, lesions had decreased in size. Three months after sonication, lesions were very small-smaller than those after immediate sonication (Fig. 2A) - and hypointense on T1-weighted images.

\section{MRI Patterns After Capsulotomy in Patients With OCD}

Patterns of MRI changes were similar in the 5 successful OCD patients, although there was 1 failed case. Lesions in the ALIC were invisible on T2-weighted or diffusion-weighted images during sonication (Fig. 1B). Capsulotomy was performed bilaterally, and lesions in the right hemisphere appeared on T2-weighted images during sonication of the left hemisphere. Lesions were hardly detected on diffusion-weighted images immediately after sonication, and mere enhancement of the lesion was presumably due to less of an opening of the blood-brain barrier compared to thalamotomy. Therefore, lesions from capsulotomy were not as prominent as those from thalamotomy soon after MRgFUS. However, 7 days after sonication, lesions became more distinct, and this enhancement was maintained for at least 1 month after sonication. Six months after sonication, lesions had decreased in size slightly and appeared small and hyperintense on T2-weighted images but were larger than that of immediate sonication (Fig. 2B).

\section{Treatment Parameters and Lesion Size}

For MRgFUS thalamotomy, a mean of 18.3 times of sonication (range 14-27) was needed with mean maximal 


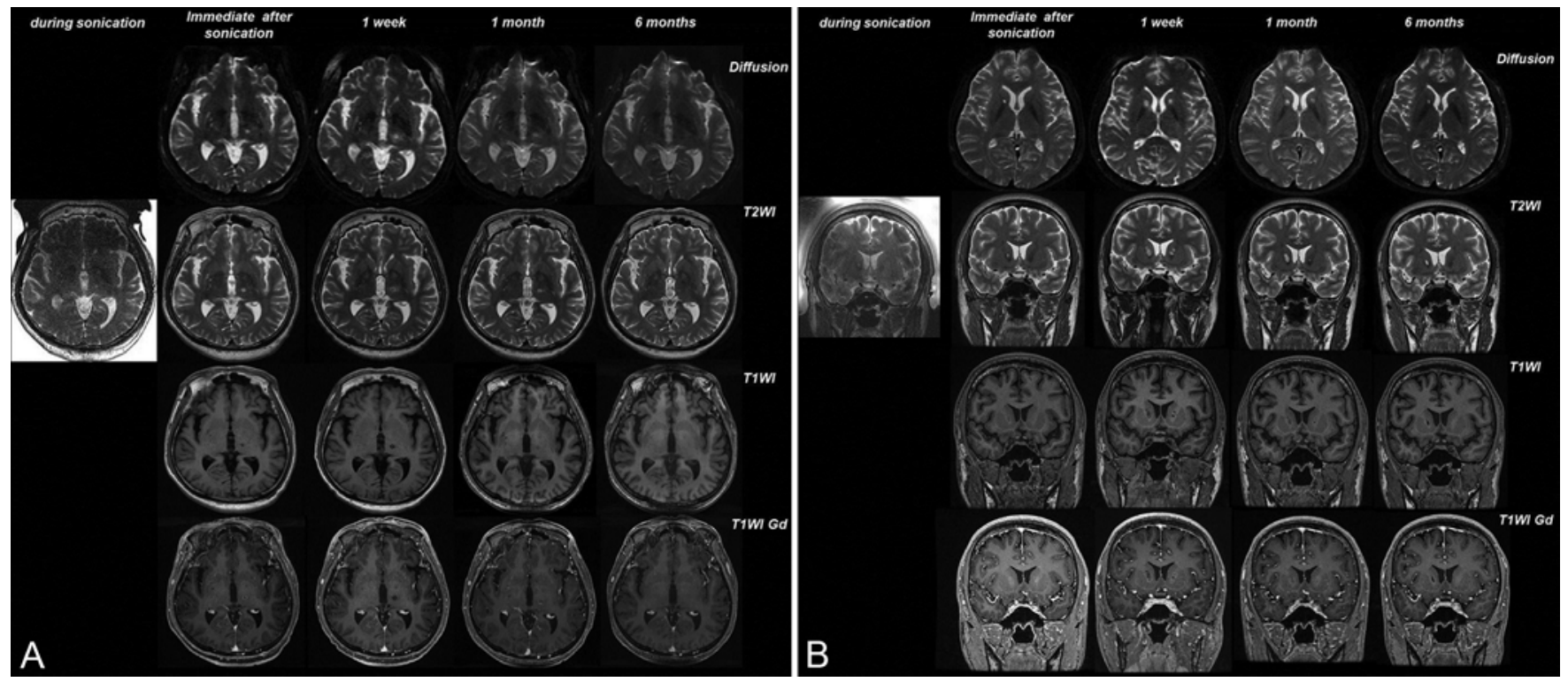

FIG. 1. Sequential MR images after transcranial MRgFUS. A: Unilateral thalamotomy. Lesions were visible during and soon after sonication but not 6 months later. B: Bilateral anterior limb capsulotomy. Lesions were not visible during sonication but emerged after sonication. Six months after treatment, lesions had reduced in size but were still visible.

energy of $15347.9 \pm 4157.7 \mathrm{~J}$, which raised the temperature to a mean of $56^{\circ} \mathrm{C}$ (range $54^{\circ}-60^{\circ} \mathrm{C}$ ) on MR thermometry. The mean lesion volume was $72.9,233.3,100.8$, and $20.1 \mathrm{~mm}^{3}$, respectively, at postsonication immediately, 1 week, 1 month, and 3 months after MRgFUS.

For MRgFUS capsulotomy, a mean of 14.6 times of sonication (range 8-22) was needed with mean maximal energy of $16969.2 \pm 7418.5 \mathrm{~J}$, which raised the temperature to mean $53.6^{\circ} \mathrm{C}$ (range $51^{\circ}-60^{\circ} \mathrm{C}$ ) on MR thermometry. The mean lesion volume was 38.0, 208.2, 129.4, and $51.5 \mathrm{~mm}^{3}$, respectively, at postsonication immediately, 1 week, 1 month, and 6 months after MRgFUS.

Three months after MRgFUS thalamotomy, followup MRI showed that the lesion volume had become very small, smaller than that of immediate postsonication volume. Six months after MRgFUS capsulotomy, the lesion also shrunk but was larger than that of immediate postsonication (Fig. 3). Treatment parameters and serial lesion volumes for each patient are presented in Table 1.

\section{Description of Failed Cases}

The acoustic energy beams from each 1024 transducer element passed through the skull surface. We used the system software to obtain skull surface data and performed calculations based on the Hounsfield unit scale (Fig. 4). Skull marrow thickness was divided by average thickness between the outer and inner cortical bone. This ratio ranged from 0.15 to 0.71 . If this cortical-to-bone marrow thickness ratio was less than 0.4 , there was a higher probability of temperature rise failure. If this ratio was less than 0.3 , maximal temperature never rose above $45^{\circ} \mathrm{C}$ (Fig. 5).

\section{Discussion}

Magnetic resonance-guided focused ultrasound is an innovative technique in functional neurosurgery because it allows precise, image-guided targeting and thermal lesioning of deep brain structures. ${ }^{18}$ Temperature maps generated by the MRI scanner permit the verification of the location of thermal rise and thermal ablation. To assess the safety, feasibility, and efficacy of this technology in the brain, the precision of thermal lesioning is one of the most important factors enabling a successful outcome. Currently, neuropathic pain, ET, Parkinson's disease, and OCD are considered ideal conditions for MRgFUS because the necessary volume of lesioning is relatively small, thus requiring less energy to achieve therapeutic efficacy. ${ }^{13,16,18,19}$

\section{Different MRI Patterns After MRgFUS in ET and OCD Patients}

We found different MRI patterns after MRgFUS in patients with ET and OCD. For ET patients who received Vim thalamotomy, lesions were clearly visible in MR images during and immediately after sonication. In contrast, for OCD patients who received ALIC capsulotomy, lesions were less visible during and immediately after sonication. However, a lesion in the right hemisphere (i.e., the first site of sonication) could be seen during left hemisphere sonication. Approximately 1-2 hours after sonication, bilateral lesions were observed in diffusion-weighted images. These different MRI patterns after MRgFUS of the Vim and ALIC seem to originate from differences between brain structures and their associated white and gray matter. ${ }^{25}$ It is well known that differences on MR sequences, such as diffusion-weighted MR images, can predict cytotoxic tissue changes at early posttreatment stages. ${ }^{4}$ At rather low temperatures (i.e., $<51^{\circ} \mathrm{C}$ ), the level of restriction on diffusion-weighted images differed between the Vim and ALIC immediately after sonication. Restriction was much more prominent in the Vim, resulting in easier detection of lesion sites. After sonication of the ALIC, however, only a small restriction could 


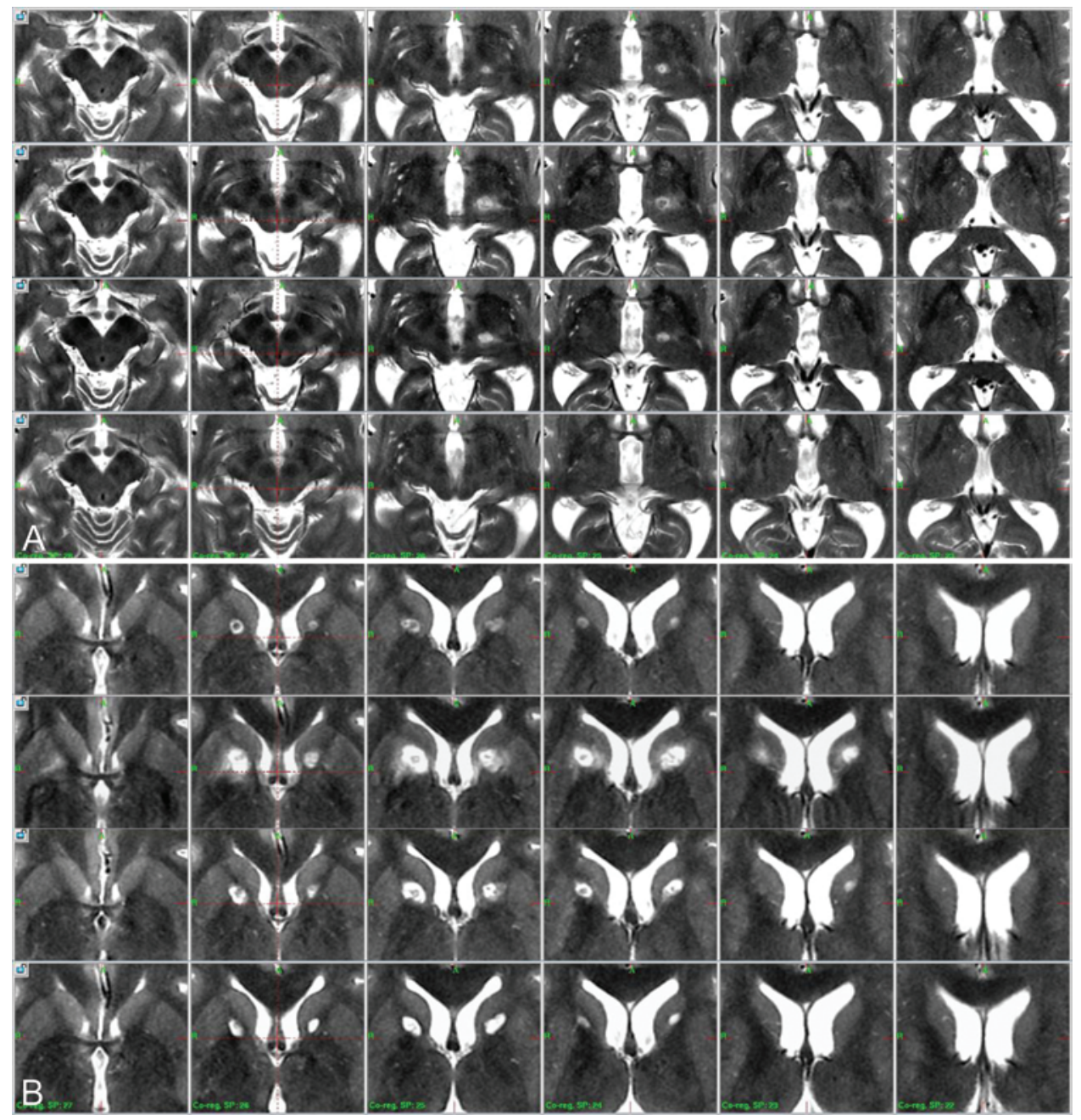

FIG. 2. Serial axial T2-weighted MR images after transcranial MRgFUS. A: Unilateral thalamotomy. B: Bilateral anterior limb capsulotomy. After MRgFUS thalamotomy and capsulotomy, both lesions exhibited maximum volume at 1 week; however, after 3 months, the thalamotomy lesion got very small, whereas the capsulotomy lesion remained at the volume seen immediately postsonication. Figure is available in color online only.

be found. The reason for these different patterns might be the different characteristics of target regions. When temperature was above $55^{\circ} \mathrm{C}$, however, as in OCD Case 4 (Table 1), the ALIC also showed prominent restrictions on diffusion-weighted images taken immediately after

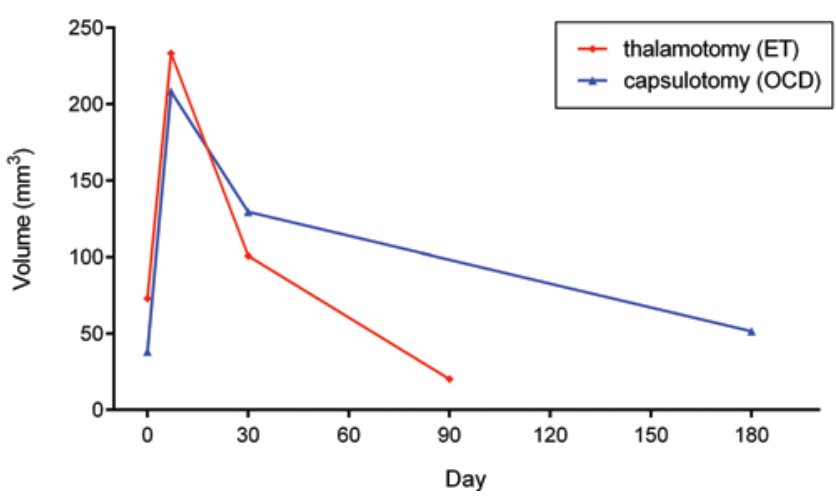

FIG. 3. The volume curve after MRgFUS thalamotomy and capsulotomy. Figure is available in color online only. sonication. Because of the abundance of myelin sheaths and axonal cellular membranes in white matter, directional water diffusion is interrupted, resulting in anisotropic water diffusion. ${ }^{26}$ In previous histological studies, white matter was found to be more readily affected by ultrasound, with gray matter requiring higher ultrasonic dosages to produce changes. ${ }^{8}$ In our study, because ET patients experienced a greater rise in temperature than OCD patients, the exact energy delivery cannot be compared between groups. However, when lesion size was measured within $50^{\circ} \mathrm{C}$ thermal contours, the initial lesion size was larger for thalamotomy-treated patients than for capsulotomy-treated patients, with this pattern reversing as time passed.

Previous studies employing MRI after sonication show a temporal delay of imaging changes depending on tissue type and location..$^{2,3,6,7,20}$ Our results are in line with these previous findings. However, no previous studies have reported differences in MRI patterns depending on brain region in humans. Previous animal studies confirm the stability of thermal lesions with minimal associated ede- 
TABLE 1. Treatment parameters and serial lesion volume measured on T2-weighted MRI after MRgFUS unilateral thalamotomy and bilateral capsulotomy in successful cases

\begin{tabular}{|c|c|c|c|c|c|c|c|c|}
\hline \multirow[b]{2}{*}{ Case No. } & \multirow{2}{*}{$\begin{array}{c}\text { Total } \\
\text { Sonication No. }\end{array}$} & \multirow{2}{*}{$\begin{array}{l}\text { Maximal } \\
\text { Energy }(\mathrm{J})\end{array}$} & \multirow{2}{*}{$\begin{array}{c}\text { Temperature } \\
\left(\text { mean } / \max { }^{\circ} \mathrm{C}\right)\end{array}$} & \multicolumn{5}{|c|}{ Lesion Vol $\left(\mathrm{mm}^{3}\right)$ in T2 MRI* } \\
\hline & & & & Postop & $7 d$ & $30 d$ & $90 d$ & $180 d$ \\
\hline \multicolumn{9}{|l|}{ ET patients } \\
\hline 1 & 17 & 14,250 & $55 / 60$ & 54.3 & 177 & 92.5 & 3.8 & - \\
\hline 2 & 16 & 15,510 & $54 / 60$ & 56.6 & 186.5 & 86.8 & 24.1 & - \\
\hline 3 & 27 & 23,900 & $55 / 59$ & 18.8 & 163.1 & 135.2 & 87.2 & - \\
\hline 4 & 23 & 15,733 & $55 / 59$ & 106.4 & 265.2 & 67.4 & 4.8 & - \\
\hline 5 & 19 & 15,790 & $55 / 57$ & 39.3 & 160.2 & 36.6 & 6.8 & - \\
\hline 6 & 14 & 8800 & $60 / 65$ & 158.7 & 425 & 121.7 & 6.3 & - \\
\hline 7 & 16 & 15,300 & $57 / 60$ & 65.9 & 202.9 & 144 & 2.7 & - \\
\hline 8 & 14 & 13,500 & $57 / 60$ & 83.4 & 286.5 & 122.5 & 26.1 & - \\
\hline Mean & & & & 72.9 & 233.3 & 100.8 & 20.2 & - \\
\hline \multicolumn{9}{|c|}{ OCD patients } \\
\hline $1 \mathrm{rt}$ & 20 & 12,281 & $60 / 64$ & 56.4 & 274.2 & 215.4 & - & 69.9 \\
\hline $1 \mathrm{lt}$ & 8 & 10,834 & $51 / 54$ & 11.6 & 100.4 & 90.4 & - & 12.1 \\
\hline $2 \mathrm{rt}$ & 22 & 13,674 & $52 / 54$ & 7.9 & 106.8 & 44 & - & 10.3 \\
\hline 2 It & 14 & 22,059 & $51 / 53$ & 4.5 & 75.7 & 25.7 & - & 5.2 \\
\hline $3 \mathrm{rt}$ & 22 & 28,085 & $51 / 53$ & 5.6 & 21.8 & 13.9 & - & 3.6 \\
\hline 3 It & 14 & 28,139 & $52 / 54$ & 4.9 & 87.7 & 33.5 & - & 10 \\
\hline $4 \mathrm{rt}$ & 14 & 8700 & $56 / 59$ & 116.4 & 396.3 & 259.1 & - & 142.7 \\
\hline 4 It & 9 & 8450 & $55 / 59$ & 66.5 & 296.8 & 199.3 & - & 133.8 \\
\hline $5 \mathrm{rt}$ & 14 & 20,040 & $55 / 58$ & 62.6 & 392.2 & 248.9 & - & 74.2 \\
\hline $5 \mathrm{lt}$ & 9 & 17,430 & $53 / 58$ & 44.4 & 330.4 & 164 & - & 52.7 \\
\hline Mean & & & & 38.0 & 208.2 & 129.4 & - & 51.5 \\
\hline
\end{tabular}

$\mathrm{d}=$ days; - = not applicable.

* Lesion volume was measured with Leksell GammaPlan version 10.1 (Elekta).

ma or damage to adjacent structures. ${ }^{4,20}$ However, these studies focused mainly on white matter lesions. Thus, there has been no study in humans comparing different effects of sonication in white and gray brain matter.

Another interesting finding in the present study is that prominent lesions were observed 7 days after MRgFUS capsulotomy in OCD patients even though they were not obvious immediately after treatment. This delayed emergence of lesions may originate from demyelination during the subacute and chronic phases of injury. That is, white matter lesions may initially appear more subtle than gray matter lesions. However, unlike direct damage to neurons in the gray matter, damage to the white matter may manifest more slowly and become prominent at later delays. Consistent with this possibility, a previous study in rats showed noticeably absent myelin and oligodendrocytes in injured brain areas 1 week after injury, with these changes persisting for up to 56 days. ${ }^{24}$

Because MRgFUS is a closed-loop procedure, neurological function and also the site and size of lesions can be monitored during treatment using MRI. During thalamotomy for ET patients, we monitored hand tremors, sensory changes, and motor function. However, during ALIC capsulotomy for OCD patients, we could not monitor patients due to their disease characteristics and the effect of capsulotomy on surrounding structures. Therefore, the prediction of lesion size is important for target regions such as the ALIC. We found that lesion volume persisted at 6 months after MRgFUS capsulotomy, and the final volume was similar to that of immediate postsonication. As shown in Fig. 1B, the right-side capsulotomy lesion, which was made first, was merely visible during or at the end of right capsulotomy. Good clinical results were reported when the deep brain stimulation site was close to the ventral striatum/ventral capsule. ${ }^{9,22,23}$ Therefore, given the posttreatment delay in the appearance of the lesion and given the persistent posttreatment lesion volume, MRI-documented characteristics can help guide the approach with MRgFUS for capsulotomy.

\section{Factors Related to Insufficient Temperature Rise}

The skull is a major barrier to thermal or mechanical tissue destruction surgery, thus previously necessitating a skull window. ${ }^{8,10,15}$ With the introduction of MRgFUS, elevations in temperature can be achieved without a skull window..$^{12}$ However, heterogeneous aspects of the human skull such as volume, thickness, density, and shape are possible causes of defocusing, which could lead to insufficient temperature rise. ${ }^{5,21}$ The transmission of ultrasound through the skull is reduced by the intrinsic absorption of acoustic energy by the bone and the reflection of energy at the inner and outer tables or the trabecular level of the skull. Furthermore, the target location and related 

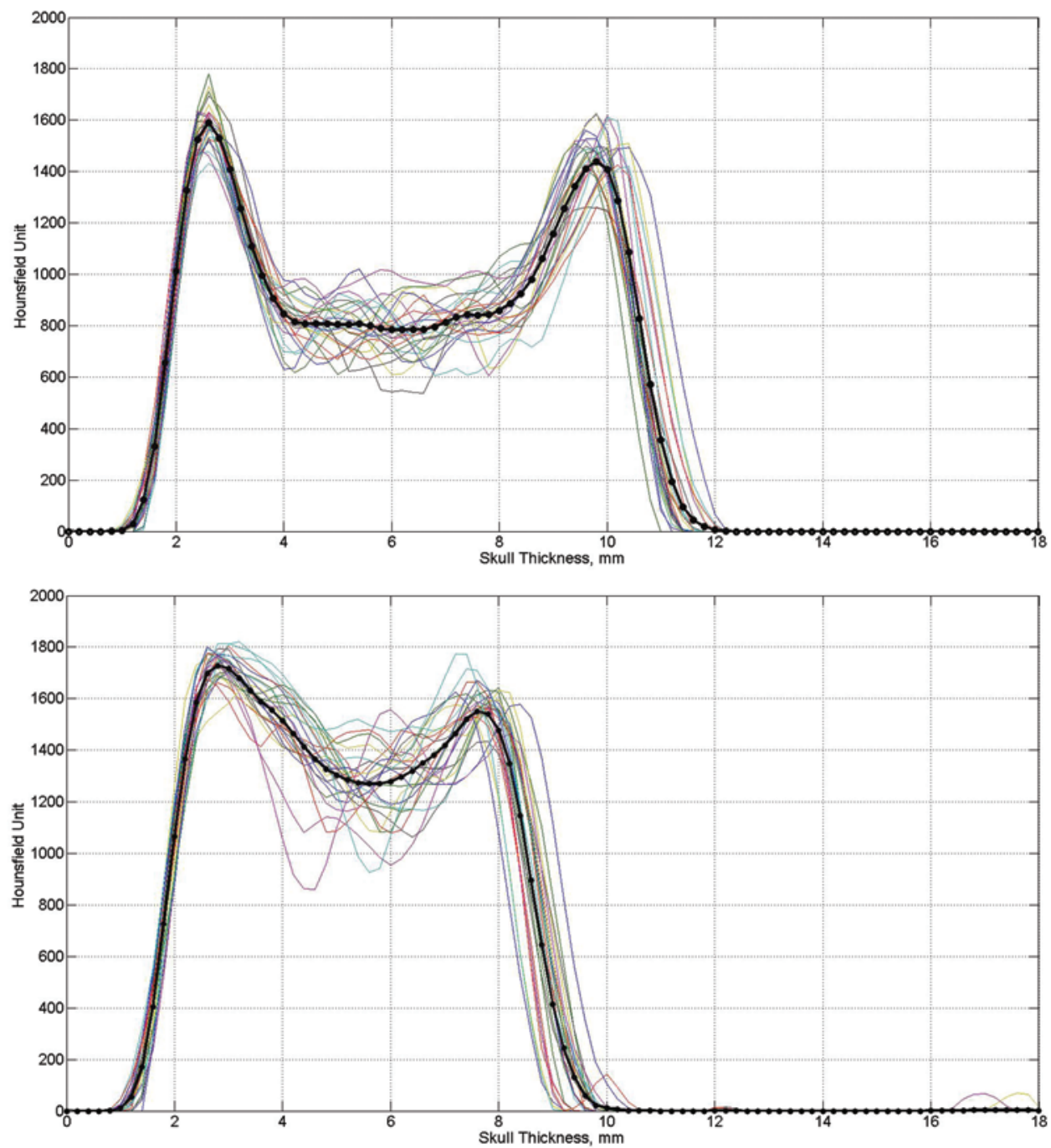

FIG. 4. Measurement of skull density. The Hounsfield unit for skull marrow was divided by the average value between the outer and inner cortical bone. Upper: The cortical-to-bone marrow thickness ratio was 0.43 . Lower: The cortical-to-bone marrow thickness ratio was 0.77 . Figure is available in color online only.

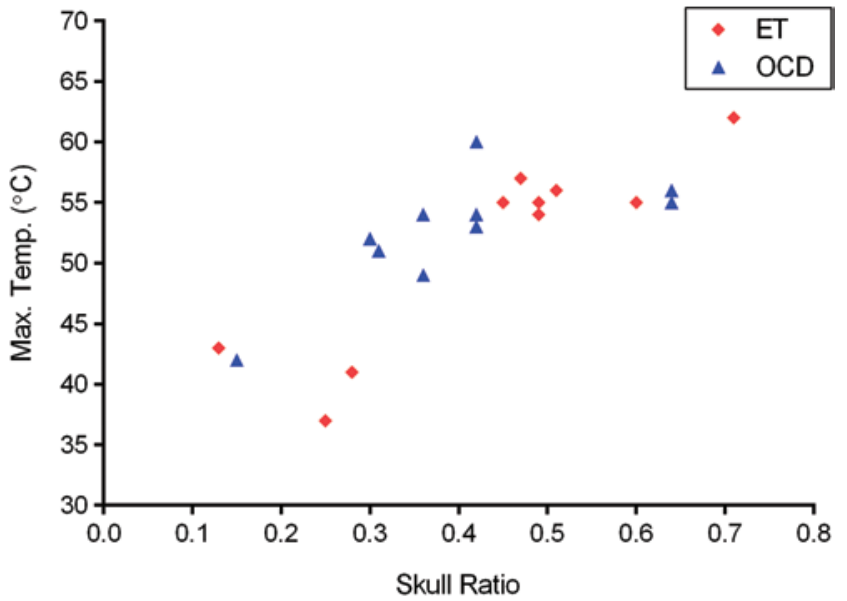

FIG. 5. Correlation between maximal temperature and cortical-to-bone marrow thickness ratio. Data are from $11 \mathrm{ET}$ patients (unilateral lesion) and 6 OCD patients (bilateral lesion). For the 3 failed ET cases and 1 failed OCD case, mean skull ratio was 0.3 and maximal temperature was less than $45^{\circ} \mathrm{C}$. Figure is available in color online only. acoustic energy beams' characteristics (e.g., ray angle to the skull, distance from transducer to the skull) may also affect energy delivery.

Some previous MRgFUS studies have used calvariae from cadavers to overcome differences in skull characteristics using CT-based skull-specific aberration corrections. ${ }^{11,14,17}$ Although we have experience in performing MRgFUS using the ExAblate 4000, we still had some limitations related to patient characteristics. Among our 4 failed cases, we examined the simple but clinically important factor of skull density, which entails not only the skull medium but also skull thickness. We obtained these data not only from ET patients who had unilateral MRgFUS but also from OCD patients who had bilateral MRgFUS, showing that maximal temperature after final sonication differed between hemispheres within the same patient and indicating that skull density is not the only barrier. Apart from skull density, other suspected causes of variation, such as acoustic energy beams' angles to the skull or homogeneity of marrow or trabeculae form, should be investigated in the near future. Furthermore, 
much more data are needed to clarify and confirm these possible limitations of MRgFUS treatment.

\section{Conclusions}

We found different MRI patterns between Vim thalamotomy in ET patients and ALIC capsulotomy in OCD patients after MRgFUS, suggesting that different anatomical targets should be approached using unique sonication strategies to maximize the efficacy of MRgFUS. Although transcranial MRgFUS for ET and OCD has great potential, there are obstacles to overcome that are related to individual differences in skull characteristics, such as skull density.

\section{Acknowledgments}

We thank Eun Jeong Kweon, RN, Sang Keum Park, RN, Young Chul Na, MD, Won Hee Lee, MD, and Ji Hee Kim, MD, for providing clinical assistance.

\section{References}

1. Chang WS, Jung HH, Kweon EJ, Zadicario E, Rachmilevitch I, Chang JW: Unilateral magnetic resonance guided focused ultrasound thalamotomy for essential tremor: practices and clinicoradiological outcomes. J Neurol Neurosurg Psychiatry [epub ahead of print], 2014

2. Chen L, Bouley D, Yuh E, D'Arceuil H, Butts K: Study of focused ultrasound tissue damage using MRI and histology. J Magn Reson Imaging 10:146-153, 1999

3. Cline HE, Schenck JF, Watkins RD, Hynynen K, Jolesz FA: Magnetic resonance-guided thermal surgery. Magn Reson Med 30:98-106, 1993

4. Cohen ZR, Zaubermann J, Harnof S, Mardor Y, Nass D, Zadicario E, et al: Magnetic resonance imaging-guided focused ultrasound for thermal ablation in the brain: a feasibility study in a swine model. Neurosurgery 60:593-600, 2007

5. Connor CW, Clement GT, Hynynen K: A unified model for the speed of sound in cranial bone based on genetic algorithm optimization. Phys Med Biol 47:3925-3944, 2002

6. Darkazanli A, Hynynen K, Unger EC, Schenck JF: On-line monitoring of ultrasonic surgery with MR imaging. J Magn Reson Imaging 3:509-514, 1993

7. Farahani K, Mischel PS, Black KL, De Salles AA, Anzai Y, Lufkin RB: Hyperacute thermal lesions: MR imaging evaluation of development in the brain. Radiology 196:517-520, 1995

8. Fry WJ, Barnard JW, Fry EJ, Krumins RF, Brennan JF: Ultrasonic lesions in the mammalian central nervous system. Science 122:517-518, 1955

9. Greenberg BD, Gabriels LA, Malone DA Jr, Rezai AR, Friehs GM, Okun MS, et al: Deep brain stimulation of the ventral internal capsule/ventral striatum for obsessive-compulsive disorder: worldwide experience. Mol Psychiatry 15:64-79, 2010

10. Heimburger RF: Ultrasound augmentation of central nervous system tumor therapy. Indiana Med 78:469-476, 1985

11. Hertzberg Y, Volovick A, Zur Y, Medan Y, Vitek S, Navon G: Ultrasound focusing using magnetic resonance acoustic radiation force imaging: application to ultrasound transcranial therapy. Med Phys 37:2934-2942, 2010

12. Hynynen K, Clement GT, McDannold N, Vykhodtseva N, King R, White PJ, et al: 500-element ultrasound phased array system for noninvasive focal surgery of the brain: a preliminary rabbit study with ex vivo human skulls. Magn Reson Med 52:100-107, 2004
13. Jeanmonod D, Werner B, Morel A, Michels L, Zadicario E, Schiff G, et al: Transcranial magnetic resonance imagingguided focused ultrasound: noninvasive central lateral thalamotomy for chronic neuropathic pain. Neurosurg Focus 32(1):E1, 2012

14. Jones RM, O'Reilly MA, Hynynen K: Transcranial passive acoustic mapping with hemispherical sparse arrays using CT-based skull-specific aberration corrections: a simulation study. Phys Med Biol 58:4981-5005, 2013

15. Lele PP: A simple method for production of trackless focal lesions with focused ultrasound: physical factors. J Physiol 160:494-512, 1962

16. Lipsman N, Schwartz ML, Huang Y, Lee L, Sankar T, Chapman M, et al: MR-guided focused ultrasound thalamotomy for essential tremor: a proof-of-concept study. Lancet Neurol 12:462-468, 2013

17. Marsac L, Chauvet D, Larrat B, Pernot M, Robert B, Fink M, et al: MR-guided adaptive focusing of therapeutic ultrasound beams in the human head. Med Phys 39:1141-1149, 2012

18. Martin E, Jeanmonod D, Morel A, Zadicario E, Werner B: High-intensity focused ultrasound for noninvasive functional neurosurgery. Ann Neurol 66:858-861, 2009

19. Monteith S, Sheehan J, Medel R, Wintermark M, Eames M, Snell J, et al: Potential intracranial applications of magnetic resonance-guided focused ultrasound surgery. A review. J Neurosurg 118:215-221, 2013

20. Mórocz IA, Hynynen K, Gudbjartsson H, Peled S, Colucci V, Jólesz FA: Brain edema development after MRI-guided focused ultrasound treatment. J Magn Reson Imaging 8: 136-142, 1998

21. Pichardo S, Sin VW, Hynynen K: Multi-frequency characterization of the speed of sound and attenuation coefficient for longitudinal transmission of freshly excised human skulls. Phys Med Biol 56:219-250, 2011

22. Rauch SL: Neuroimaging and neurocircuitry models pertaining to the neurosurgical treatment of psychiatric disorders. Neurosurg Clin N Am 14:213-223, vii-viii, 2003

23. Sturm V, Lenartz D, Koulousakis A, Treuer H, Herholz K, Klein JC, et al: The nucleus accumbens: a target for deep brain stimulation in obsessive-compulsive- and anxietydisorders. J Chem Neuroanat 26:293-299, 2003

24. Sundberg LM, Herrera JJ, Narayana PA: In vivo longitudinal MRI and behavioral studies in experimental spinal cord injury. J Neurotrauma 27:1753-1767, 2010

25. Zatorre RJ, Fields RD, Johansen-Berg H: Plasticity in gray and white: neuroimaging changes in brain structure during learning. Nat Neurosci 15:528-536, 2012

26. Zhang F, Lu GM, Zee CS: Comparative study of the sensitivity of ADC value and $\mathrm{T}_{2}$ relaxation time for early detection of Wallerian degeneration. Eur J Radiol 79:118-123, 2011

\section{Author Contributions}

Conception and design: JW Chang, Jung, Rachmilevitch. Acquisition of data: Jung, WS Chang, Rachmilevitch. Analysis and interpretation of data: Jung, WS Chang, Rachmilevitch, Tlusty, Zadicario. Drafting the article: JW Chang, Jung. Critically revising the article: JW Chang, Jung. Reviewed submitted version of manuscript: all authors. Approved the final version of the manuscript on behalf of all authors: JW Chang. Administrative/technical/material support: Jung, Rachmilevitch, Tlusty, Zadicario. Study supervision: JW Chang, Jung.

\section{Correspondence}

Jin Woo Chang, Department of Neurosurgery, Yonsei University College of Medicine, 134 Shinchon-dong, Seodaemun-gu, Seoul 120-752, Korea. email: jchang@yuhs.ac. 